\title{
Administration time of misoprostol affects fertility rate in artificially inseminated Kivircik ewes with frozen-thawed ram semen
}

\author{
Hakan Ustuner ${ }^{1}$, Burcu Ustuner ${ }^{2,4}$, M. Berk Toker ${ }^{2}$, Selim Alcay ${ }^{2}$, Kamber Demir $^{3}$, Hakan Sagirkaya ${ }^{2}$, \\ Zekariya Nur ${ }^{2}$
}

\begin{abstract}
${ }^{1}$ Department of Animal Science, Faculty of Veterinary Medicine, Uludag University, Gorukle/Bursa, 16059, Turkey.
${ }^{2}$ Department of Reproduction and Artificial Insemination, Faculty of Veterinary Medicine, Uludag University, Gorukle/Bursa, 16059, Turkey.

${ }^{3}$ Department of Reproduction and Artificial Insemination, Faculty of Veterinary Medicine, Istanbul University, Avcilar/Istanbul, 16059, Turkey.
\end{abstract}

\begin{abstract}
The aim of this study was to determine the effects of the administration time of misoprostol $(11 \mathrm{~h}$ (Miso11) and $6 \mathrm{~h}$ (Miso6) before artificial insemination) on fertility rates in Kivircik ewes (control: $\mathrm{n}=41$, Miso11: $\mathrm{n}=32$ and Miso6: $\mathrm{n}=33$ ) during breeding season. Artificial insemination (AI) was performed $48 \mathrm{~h}$ after sponge removal using frozen-thawed semen (150 million sperm per dose in $0.25 \mathrm{ml}$ straws). Estrus synchronization parameters (onset and duration) and lambing rate were evaluated. No significant difference was observed among groups for the estrus onset and duration hours $(\mathrm{P}>0.05)$. The lambing rates in the control, Miso11 and Miso6 groups were 39.0, 62.5 and $54.5 \%$, respectively. There were significant differences among the control, Miso11 and Miso6 groups according to lambing rates $(\mathrm{P}<0.05)$. In conclusion, misoprostol treatment significantly improved fertility in ewes when using frozen-thawed semen in AI. Administration of misoprostol $11 \mathrm{~h}$ before AI resulted in a higher lambing rate than that at $6 \mathrm{~h}$ before AI; therefore, treatment of misoprostol $11 \mathrm{~h}$ before AI can effectively be used.
\end{abstract}

Keywords: artificial insemination, Kivircik ewe, misoprostol.

\section{Introduction}

The genetic progress in farm animals may be possible with the widespread use of artificial insemination (AI) with the highest quality frozenthawed semen from genetically superior males. Cryopreservation has been reported to cause changes in sperm morphology, including damage to mitochondria, acrosome and sperm tail (Wooley and Richardson, 1978). Therefore, fertility results of deep cervical AI with frozen-thawed semen are low, and obtaining good fertility with frozen-thawed semen requires insemination directly into the uterus (O'Connell et al., 2002).

The ewe cervix is a long and fibrous tubular organ. Due to the presence of 4-7 cervical rings in the lumen, its caudal opening provides a physical barrier to external contaminants. The convolute and tortuous structure catheter entrance is more difficult than in the cow (Wulster-Radcliffe et al., 2004; Kershaw et al.,
2005; Leethongdee, 2010; Aral et al., 2011).

The rate of AI achievement in sheep may vary between 76 and 10\% (Windsor, 1995; Kershaw et al., 2005) depending on breeds. Such different success of AI among individual ewes may be explained by the great variation in cervical anatomy among animals (Kershaw et al., 2005). There are considerable differences between species, even each breed of sheep regarding the complexity of cervical rings, organization of the inner and outer orifices, length and complexity of the cervical lumen and anatomical relationships with the uterine body and vagina (Leethongdee et al., 2007).

We know that the cervix functions through the remodeling of the extracellular matrix components, such as dissociation of collagen fibers, degradation of proteoglycans and the release of glycosaminoglycans (GAGs), specifically during late gestation, parturition and estrus (Leppert, 1992; Leethongdee, et al., 2010). Hyaluronan is the predominant GAG, whose synthesis is stimulated by Prostoglandin E2 in the sheep cervix (Dobson, 1988) and its concentrations vary during the estrus cycle (Kershaw-Young et al., 2009). Hyaluronan content of the cervix has been reported to be the highest prior to the preovulatory LH surge of the estrus cycle, when there is also a degree of natural relaxation of the cervix (Leethongdee et al., 2007). Recent researches showed that intravaginal application of a PGE1 analogue, such as misoprostol, after estrus synchronization can induce cervical ripening, which has a direct correlation with the rate of resulted pregnancy, and is greater when the catheter reaches the uterus (Leethongdee et al., 2007; Horta et al., 2010).

The misoprostol is generally administered $6 \mathrm{~h}$ before artificial insemination to increase the cervical depth penetration in different sheep breeds (Aral et al., 2011). A longer time lag between treatment and AI may be required to avoid drugs interference on semen performance and to allow maximal biochemical and structural transformations of the cervix to occur before AI. However, limited reference information exists regarding the effect of misoprostol on the fertility rates of Kivircik ewes. Thus, the objective of this study was to determine the effects of the administration time of misoprostol (6 and $11 \mathrm{~h}$ before artificial insemination) on fertility rates following fixed-time artificial insemination. 


\section{Materials and Methods}

The Scientific Ethical Committee (Uludag University, Bursa, Turkey, No: 2012-14/3) approved all protocols related to the experimental setup and evaluation techniques. The experiment was carried out at an experimental commercial farm, $\left(38^{\circ} 28^{\prime} 52^{\prime \prime} \mathrm{N}\right.$ latitude and $28^{\circ} 81^{\prime \prime} \mathrm{E}$ longitude ) in Manisa, Turkey, during the breeding season (July) under natural lighting. In this study, 106 clinically healthy Kivircik ewes ( 2 to 4 years old), 5 fertile Kivircik rams for semen collection and 6 teaser rams for estrus detection were used. The teaser rams were used rotationally (changed daily). The ewes were group- housed in an open barn. All ewes were fed with a commercial concentrate diet with hay and water provided ad libitum. Ewes were kept away from the rams to prevent voluntary mating. In the meantime, a teaser ram was introduced to the flock for a short time $(1 \mathrm{~h})$ on each occasion (once or twice weekly) to determine the presence of estrus cyclicality in season. Body weights and condition scores of these animals were recorded prior to the experiment. Ewes weighing between 45 to $55 \mathrm{~kg}$ with good body conditions (BCS:3 to 3.5 ) were used.

\section{Intra-cervical application of misoprostol}

All ewes were treated with intravaginal sponges containing $40 \mathrm{mg}$ of progesterone $(40 \mathrm{mg}$ of FGA ${ }^{\circledR}$ Fluorogestone Acetate, Intervet Productions SA, Lyons, France) for 12 days. The injection of $250 \mu \mathrm{g} / \mathrm{ml}$ of PGF $2 \alpha$ analog cloprostenol (1 $\mathrm{ml}$ of Juramate, Jurox Pty Ltd, Australia) was applied $24 \mathrm{~h}$ before sponge removal. An i.m injection of 400 IU of PMSG (Intervet Productions SA., Lyons, France) was given at sponge removal to induce and synchronize heat. Ewes $(n=106)$ were divided into three groups. Ewes in the control group $(n=41)$ were not treated, but the procedure was carried out without administering a tablet. Ewes in groups $11 \mathrm{~h}$ (Miso11, $\mathrm{n}=32$ ) and $6 \mathrm{~h}$ (Miso6, $\mathrm{n}=33$ ) had one pill of Cytotec $(200 \mu \mathrm{g}$ of misoprostol, Cytotec $^{\circledR}$; Pfizer, England) inserted into the vagina before AI, corresponding to 37 and $42 \mathrm{~h}$ after sponge removal, respectively. For the misoprostol treatment; ewes were restrained in a yoke fitted with side bars to minimize lateral and forward movements, with their hindquarters raised about 4 inches. The perineum was cleaned with a disinfectant wipe and, using a vaginal speculum, misoprostol tablet was placed at the external os of the cervix with the help of long forceps. Each ewe was restrained during the administration of misoprostol tablet for no more than $5 \mathrm{~min}$ to minimize the stress on the ewes.

\section{Observation of estrus signs}

Ewes were monitored every $6 \mathrm{~h}$ for $1 \mathrm{~h}$, starting from 12 to $80 \mathrm{~h}$ after sponge removal, for both the signs of estrus behavior and their durations with the aid of teaser rams. Ewes were considered in estrus when they allowed the male to mount. Estrus duration was defined as the time elapsed between the first and last accepted mount within the same estrus period.

\section{Semen collection, freezing and artificial insemination}

Five rams with previously proven fertility were used for semen collection with the electroejaculator (Minitube-Germany). To collect semen, each ram was physically restrained, and a lubricated probe was inserted into the rectum with downward pressure being maintained on the front of the probe, so the electrodes remained near the upper portion of the ampullary region (Ustuner et al., 2016). When the electrostimulation was stopped briefly, further massage was applied with the probe. This cycle was repeated until 1.5-2 $\mathrm{ml}$ of semen was collected (usually 3-4 electrostimulations). Collected semen was placed in a warm water bath $\left(30^{\circ} \mathrm{C}\right)$ and evaluated immediately for consistency, wave motion (0-5 scale) and percentage of motile spermatozoa (\%). Ejaculates with a thick consistency, only $0.5-1.5 \mathrm{ml}$ of sperm with rapid wave motion (2-5 on a $0-5$ scale), and $>70 \%$ initial motility were pooled and diluted with a Tris-based extender $(20 \%$ egg yolk; $\mathrm{v} / \mathrm{v}$ ) to a final concentration of 1:5 (semen:extender) in $6 \%$ glycerol using a two-step dilution method (Aisen et al., 2000). The semen samples were frozen in $0.25 \mathrm{ml}$ straws in liquid nitrogen vapor using a Nicool Plus PC freezing machine (Air Liquide, Marne-la-Valle'e Cedex 3 , France), and then they were plunged into liquid nitrogen at $-196^{\circ} \mathrm{C}$.

The straws were thawed at $37^{\circ} \mathrm{C}$ for $30 \mathrm{sec}$ in a water bath for insemination of ewes. In total, $0.25 \mathrm{ml}$ corresponding to 150 million sperm cells with at least 45 to $50 \%$ progressive motility was delivered to each ewe. Intra-cervical artificial insemination was performed $48 \mathrm{~h}$ after sponge removal, with $0.25 \mathrm{ml}$ straws. Cervical AI was considered when semen was deposited at least after the first cervical ring.

\section{Lambing rate}

Lambing rates (percentage of ewes lambing) were recorded following $150 \pm 5$ days of inseminations. Lambing rates were calculated as follows: lambing rate $=($ lambs born/ewes inseminated $) \times 100$ (Zeleke et al. 2005).

\section{Statistical analysis}

The onset of estrus and duration were subjected to an analyses of variance (one-way ANOVA), and the differences among means were tested for significance by Tukey's test. Lambing rates were analyzed using the chi-square test.

\section{Results}

The results in terms of estrus response for the time to the onset and duration of the induced estrus and lambing rates are set out in Table 1. No significant difference was observed among groups for the estrus onset and duration hours $(\mathrm{P}>0.05)$.

As shown in Table 1 and Fig. 1, the lambing 
rate was $39.0 \%$ in control group, $62.5 \%$ in the Miso 11 group and $54.5 \%$ in the Miso6 group. There were significant differences among the control, Miso11 and Miso6 groups according to lambing rates $(\mathrm{P}<0.05)$. The 7.9\% improvement in Miso11 fertility when compared to the Miso6 fertility depended on a more comfortable passage of the cervix.
Table 1. Onset and duration of estrus (h) and lambing rate $(\%)$ of ewes in relation to the administration of misoprostol 11 and $6 \mathrm{~h}$ prior to insemination (control vs. treatment).

Figure1. Lambing rate (\%) of ewes in relation to administration of misoprostol 11 and $6 \mathrm{~h}$ prior to insemination (control vs. treatment).

Table 1. Mean $( \pm \mathrm{SE})$ onset and duration of oestrus $(\mathrm{h})$ and lambing rate $(\%)$ of ewes in relation to administration of misoprostol 11 and $6 \mathrm{~h}$ prior to insemination (control $v s$. treatment).

\begin{tabular}{lcccc}
\hline \multicolumn{1}{c}{ Group } & $\mathrm{n}$ & Onset & Duration & Lambing rates $(\%)$ \\
\hline Control & 41 & $38.25 \pm 9.85$ & $19.13 \pm 6.72$ & $16(39.02)^{\mathrm{c}}$ \\
Miso11 & 32 & $44.89 \pm 10.83$ & $17.33 \pm 9.01$ & $20(62.50)^{\mathrm{a}}$ \\
Miso6 & 33 & $41.22 \pm 8.73$ & $20.87 \pm 9,72$ & $18(54.55)^{\mathrm{b}}$ \\
\hline
\end{tabular}

Data were presented as mean \pm SE. ${ }^{\text {a,b,c }}$ Different superscripts in the same column indicate significant differences among groups $(\mathrm{P}<0.05)$.

Lambing rate $(\%)$

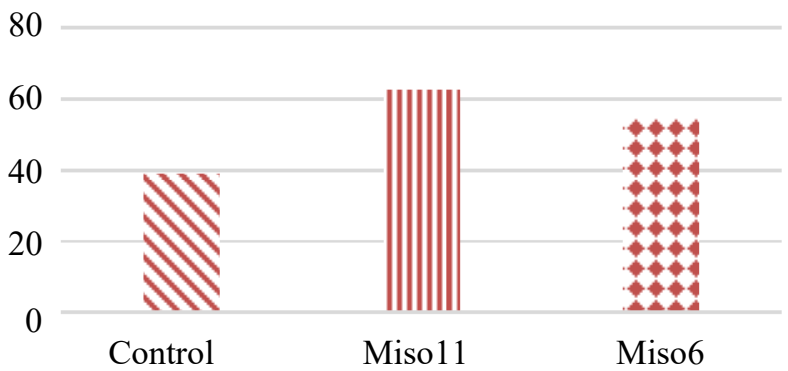

Figure 1. Lambing rate (\%) of ewes in relation to administration of misoprostol 11 and $6 \mathrm{~h}$ prior to insemination (control vs. treatment).

\section{Discussion}

Artificial insemination in sheep has two major limiting factors: the poor quality of frozen-thawed ram semen and the convoluted anatomy of the sheep cervix that does not allow transcervical passage of an insemination catheter (Falchi et al., 2012). Therefore, this investigation was conducted to determine the effect of vaginal administration time of prostaglandin E1 analogue, misoprostol, for trans-cervical artificial insemination by using frozen-thawed semen in Kivircik ewes during breeding season.

Responses to intravaginal sponges have varied according to breed, protocol, co-treatment, management, mating system and geographical location which is known to influence this period (Evans and Maxwell, 1987; Gordon, 1997). The mean estrus parameters did not differ $(\mathrm{P}>0.05)$ among the groups. In this study the time to estrus onset following the withdrawal of a sponge were 38,44 and $41 \mathrm{~h}$ in the control, Miso11 and Miso6 groups, respectively, which were longer than the $28 \mathrm{~h}$ found by Rekik et al. (2016) and similar to that found by Zeleke et al. (2005) and Zonturlu et al. (2011). Estrus duration time was shorter than reported by Ustuner et al. (2007) and similar to those reported by Zeleke et al. (2005) and Zonturlu et al. (2011).

Misoprostol influences the smooth muscle activity of the genital tract, including cervical muscle activity, which is important for sperm progression
(Hawk, 1983; Horta et al., 2010). Prostaglandins of the E series have been shown to induce collagen breakdown and softening of the cervical tissue structure, a mechanism known to be associated with local production of PGE and glycosaminoglycans (Ellwood et al., 1980; Ledger et al., 1983). It was recently proposed that prostaglandin E2 selectively binds to EP2 and EP4 prostaglandin E2 receptors, stimulating hyaluronan (HA) synthesis, which may cause remodeling of the cervical extracellular matrix and culminating in cervical relaxation (Kershaw-Young et al., 2009). In this study, the significantly higher lambing rate after the administration of misoprostol when compared to the control group strengthens the importance of the depth of insemination when using frozen-thawed semen and this was in accordance with Barbas et al. (2013). Barbas et al. (2013) reported that lambing rates of Saloia ewes treated with misoprostol after $48 \mathrm{~h}$ of synchrony $(6 \mathrm{~h}$ before AI) were 41.4 and $30.2 \%$ in treatment and control groups, respectively. The lower lambing rate of the control group than the Miso6 and Miso11 groups could be explained according to Leethongdee et al. (2007), who reported that penetration of the cervix was least at the time of sponge removal. In addition, a maximum relaxation of the cervix occurs $72 \mathrm{~h}$ after sponge removal, which is too late for the correct fixedtime artificial insemination.

The optimum time for artificial insemination of ewes is not at $72 \mathrm{~h}$ after sponge removal (Leethongdee et al., 2007). Highest fertility is achieved when ewes 
were inseminated $48-54 \mathrm{~h}$ after sponge removal (Evans and Maxwell, 1987, Ustuner et al., 2007). Therefore, the recommended treatment time of misoprostol for cervical relaxation in sheep is $6 \mathrm{~h}$ before artificial insemination (Leethongdee et al. 2007, Horta et al., 2010, Aral et al., 2011).

Frozen-thawed semen is a critical determinant of fertility, due to the significantly reduced lifespan of frozen-thawed semen in the female reproductive tract (Kumar and Naqvi, 2014). Considering the life span of the frozen sperm, it was planned that the application of misoprostol would be done $11 \mathrm{~h}$ before fixed-time artificial insemination to cervical relaxation.

This was the first time that the effect of misoprostol treatment $11 \mathrm{~h}$ before fixed-time artificial insemination with frozen-thawed semen of Kivircik ewes upon fertility was studied. In our experiment, ewes were administered misoprostol $11 \mathrm{~h}$ before artificial insemination, which resulted in a significantly higher percentage of lambing rates than the Miso6 or control groups $(\mathrm{P}<0.05)$. Although the difference of 7.9 percentage units between Miso11 and Miso6 is small in magnitude, it is certainly of practical and economic significance.

In a previous work (Rashidi and Cedden, 2013), the administration of misoprostol to ewes in estrus, $48 \mathrm{~h}$ after synchronization (3-4 $\mathrm{h}$ before insemination) resulted in a $44.87 \%$ lambing rate, which is lower than the values obtained in the present study (Miso11 $=62.5 \%$ and Miso6 = 54.5\%). Differences in fertility rates after misoprostol application in sheep may originate from the artificial insemination technique and quality of frozen-thawed sperm

This study demonstrated that misoprostol treatment significantly improves fertility in ewes when using frozen-thawed semen in AI. Administration of misoprostol $11 \mathrm{~h}$ before AI resulted in a higher lambing rate than at $6 \mathrm{~h}$ before AI. Therefore, treatment of misoprostol $11 \mathrm{~h}$ before AI can effectively be used.

\section{Acknowledgments}

This work was supported by the Agricultural Research and General Directorate of Policies (GDAR) in the scope of the National Small Ruminant Breeding Project (45KIV2011-01).

\section{Conflict of interest declaration}

There are no conflicts of interest

\section{References}

Aisen EG, Alvarez HL, Venturino A, Garde JJ 2000. Effect of trehalose and edta on cryoprotective action of ram semen diluents. Theriogenology, 53:10531061

Aral F, Temamoğulları F, Aral SS. 2011. Mechanical and pharmacologic applications of artificial insemination in ewes. Available on: http://www.intechopen.com/ books/artificial-insemination-in-farm-animals/mechanical -and-pharmacologic-applications-of-artificial-insemination -in-ewes. Accessed on: June 21, 2011.

Barbas JP, Horta AEM, Marques CC, Baptista MC, Mascarenhas RD, Martins DO, Vasques MI, Pereira RM, Cavaco-Gonçalves S. 2013. The fertility increase after misoprostol administration is differently expressed when sheep are inseminated with chilled or frozenthawed semen. Small Rumin Res, 113:398-401.

Dobson H. 1988. Softening and dilation of the uterine cervic. Oxford Rev Reprod Biol, 10:491-514.

Ellwood DA, Mitchell MD, Anderson AB, Turnbull AC. 1980. Specific changes in the in vitro production of prostanoids by the ovine cervix at parturition. Prostaglandins, 19:479-488.

Evans G, Maxwell WMC. 1987. Salamon's Artificial Insemination of Sheep and Goats. Sydney: Butterworths. pp. 34-159.

Falchi L, Taema M, La Clanche S, Scaramuzzi RJ. 2012. The pattern of cervical penetration and the effect of topical treatment with prostaglandin and/or FSH and oxytocin on the depth of cervical penetration in the ewe during the peri-ovulatory period. Theriogenology, 78:376-384.

Gordon I. 1997. Controlled Reproduction in Sheep and Goats. Wallingford, UK: CAB International. $450 \mathrm{pp}$.

Hawk HW. 1983. Sperm survival and transport in the female reproductive tract. J Dairy $S c i, 66: 2645-2660$.

Horta AEM, Barbas JP, Marques CC, Baptista MC, Vasques MI, Pereira RM, Mascarenhas RD, CavacoGoncalves S. 2010. Improvement of fertility in artificially inseminated ewes following vaginal treatment with misoprostol plus terbutaline sulphate. Reprod Domest Anim, 45:412-416.

Kershaw CM, Khalid M, McGowan MR, Ingram K, Leethongdee S, Wax G, Scaramuzzi RJ. 2005. The anatomy of the sheep cervix and its influence on the transcervical passage of an inseminating pipette into the uterine lumen. Theriogenology, 64:1225-1235.

Kershaw-Young CM, Khalid M, McGowan MR, Pitsillides AA, Scaramuzzi RJ. 2009. The mRNA expression of prostaglandin E receptors EP2 and EP4 and the changes in glycosaminoglicans in the sheep cervix during the estrous cycle. Theriogenology, 72:251-261.

Kumar D, Naqvi SMK. 2014. Effect of time and depth of insemination on fertility of Bharat Merino sheep inseminated trans-cervical with frozen-thawed semen. $J$ Anim Sci Technol, 56:8. doi:10.1186/2055-0391-56-8.

Ledger WL, Ellwood DA, Taylor MJ. 1983. Cervical softening in late pregnant sheep by infusion of prostaglandin E-2 in to a cervical artery. $J$ Reprod Fertil, 69:511-515.

Leethongdee S, Khalid M, Bhatti A, Ponglowhapan S, Kershaw CM, Scaramuzzi RJ. 2007. The effects of the prostaglandin $\mathrm{E}$ analogue isoprostol and follicle stimulating hormone on cervical penetrability in ewes during the peri-ovulatory period. Theriogenology, 67:767-777.

Leethongdee S. 2010. Development of trans-cervical artificial Insemination in sheep with special reference to anatomy of cervix. Suranaree J Sci Technol, 17:57-69.

Leethongdee S, Kershaw-Young CM, Scaramuzzi RJ, Khalid M. 2010 Intra-cervical application of 
misoprostol at estrus alters the content of cervical hyaluronan and the mRNA expression of follicle stimulating hormone receptor (FSHR), luteinizing hormone receptor (LHR) and cyclooxygenase- 2 in the ewe. Theriogenology, 73:1257-1266.

Leppert PC. 1992. Cervical softening, effacement, and dilatation: a complex biochemical cascade. J MaternalFetal Med, 1:213-233.

O'Connell M, McClure N, Lewis SEM. 2002. The effects of cryopreservation on sperm morphology, motility and mitochondrial function. Hum Reprod, 17:704-709.

Rashidi M, Cedden F. 2013. Trans-cervical artificial insemination in ewes during out of breeding season. Maced J Anim Sci, 3:143-146.

Rekik M, HaileA, Abebe A, Muluneh D, Goshme S, Ben Salem I, Hilali ME, Lassoued N, Chanyalew Y, Rischkowsky B. 2016. GnRH and prostaglandin-based synchronization protocols as alternatives to progestogen-based treatments in sheep. Reprod Domest Anim, 51:924-929.

Ustuner B, Gunay U, Nur Z, Ustuner H. 2007. Effect of long and short-term progestagen treatments with PMSG on oestrus synchronisation and fertility in Awassi ewes during the breeding season. Acta Vet Brno, 76:391-397.

Ustuner B, Alcay S, Toker MB, Nur Z, Gokce E, Ak
Sonat F, Gul Z, Duman M, Ceniz C, Uslu A, Sagirkaya H, Soylu MK. 2016. Effect of rainbow trout (Oncorhynchus mykiss) seminal plasma on the postthaw quality of ram semen cryopreservedin a soybean lecithin-based or egg yolk-based extender. Anim Reprod Sci, 164:97-104.

Windsor DP. 1995. Factors influencing the success of transcervical insemination in Merino ewes. Theriogenology, 43:1009-1018.

Wooley DM, Richardson DW. 1978. Ultrastructural injury to human spermatozoa after freezing and thawing. J Reprod Fertil, 53:389-394.

Wulster-Radcliffe MC, Wang S, Lewis GS. 2004. Transcervical artificial insemination in sheep: effects of a new transcervical artificial insemination instrument and traversing the cervix on pregnancy and lambing rates. Theriogenology, 62:990-1002.

Zeleke M, Greyling JPC, Schwalbach LMJ, Muller T, Erasmus JA. 2005. Effect of progestagen and PMSG on oestrus synchronisation and fertility in Dorper ewes during the transition period. Small Rumin Res, 56:47-53

Zonturlu AK, Ozyurtlu N, Kacar C. 2011. Effect of different doses PMSG on estrus synchronization and fertility in Awassi ewes synchronized with progesterone during the transition period. J Fac Vet Med Kafkas Univ, 17:125-129. 